\title{
Effect of Alternating Bending on Texture, Structure, and Elastic Properties of Sheets of Magnesium Lithium Alloy
}

\author{
N. M. Shkatulyak, S. V. Smirnova, and V. V. Usov \\ South Ukrainian National Pedagogical University Named after K. D. Ushinsky, 26 Staroportofrankovskaya Street, \\ Odessa 65020, Ukraine \\ Correspondence should be addressed to N. M. Shkatulyak; shkatulyak@mail.ru
}

Received 9 July 2015; Accepted 29 October 2015

Academic Editor: Manoj Gupta

Copyright (C) 2015 N. M. Shkatulyak et al. This is an open access article distributed under the Creative Commons Attribution License, which permits unrestricted use, distribution, and reproduction in any medium, provided the original work is properly cited.

The effect of low-cycle alternating bending at room temperature on the crystallographic texture, metallographic structure, and elastic properties of sheets of MgLi5 (mass) magnesium alloy after warm cross-rolling has been studied. Texture of alloy is differed from the texture of pure magnesium. The initial texture of alloy is characterized by a wide scatter of basal poles in the transverse direction. In the process of alternating bending, the changes in the initial texture and structure (which is represented by equiaxed grains containing twins) lead to regular changes in the anisotropy of elastic properties.

\section{Introduction}

Alloying of magnesium with lithium (Li) with a density of $530 \mathrm{~kg} / \mathrm{m}^{3}$ not only significantly reduces the density of $\mathrm{Mg}$ but also significantly increases the ductility and toughness of magnesium alloys [1]. Despite the fact that the effect of lithium on the microstructure and mechanical properties of magnesium alloys is known [2], many questions regarding texture formation and anisotropy of properties (in particular, elastic) for various kinds of heat treatment and deformation of magnesium alloys with lithium are yet sufficiently studied. For example, the behavior of binary alloys $\mathrm{Mg}$ - $\mathrm{Li}$ with a hexagonal structure at tension and compression is unknown, which is important for straightening sheet metal. Typically, the sheets or rolled metals are subjected to straightening by roller straightening machines. Such processing that consists of the alternating bending $(\mathrm{AB})$ reduces the internal stresses of the metal and obtaining a flat sheet [3]. There undergo substantial changes in the structure of the metal and its characteristics despite the relatively low plastic deformation during $\mathrm{AB}$. The research of these changes has important applied significance.

Effect of low-cycle alternating bending (AB) on crystallographic texture, microstructure and anisotropic properties of hexagonal magnesium alloys with aluminum and zinc (AZ31), zinc, zirconium and rare earth metals (ZE10), and titanium has been previously studied [4-9]. However, data on complex studies of the effects of the $\mathrm{AB}$ on the texture, structure, and anisotropy of elastic properties of magnesium alloys with lithium are absent.

The aim of this article is to study the effect of alternating bending on the crystallographic texture, metallographic structure and elastic properties of sheets of alloy $\mathrm{Mg}-5 \% \mathrm{Li}$ (mass) with a hexagonal lattice.

\section{Materials and Methods}

Material used for the study are the cylindrical ingots of alloy MgLi5 (mass) with a length of $120 \mathrm{~mm}$. Bars of $6 \mathrm{~mm}$ of thickness and $60 \mathrm{~mm}$ of width were received after turning and pressing of cast billets at $350^{\circ} \mathrm{C}$. Then the bars were rolled along longitudinal direction of work pieces to a thickness of $4.5 \mathrm{~mm}$ in two passes. Next rolling was carried out in the transverse direction with a reduction of $10 \%$ per pass to a thickness of $2 \mathrm{~mm}$ for 10 passes. Heating to $350^{\circ} \mathrm{C}$ was performed after each pass. Then the direction of rolling is changed in the $90^{\circ}$ one pass with a reduction of $10 \%$. 
Then again the rolling direction is changed to $90^{\circ}$ to a final thickness of $1 \mathrm{~mm}$.

The process of straightening the sheets was simulated by $\mathrm{AB}$ on a three-roll bending device. The diameter of the bending roller was $50 \mathrm{~mm}$. The speed of the motion of metal upon bending was $\sim 150 \mathrm{~mm} / \mathrm{s}$. One cycle of bending consisted of bending in one direction $(0.25$ cycle $)$, returning to the flat state $(0.5$ cycle), bending in the direction $(0.75$ cycle), and straightening (1.0 cycle). Rectangular samples of size $100 \times$ $10 \mathrm{~mm}$ were cut out from the initial sheet and deformed by $\mathrm{AB}$ with $0.5,1,3$, and 5 cycles through every $15^{\circ}$ from the last rolling direction (RD) up to transverse direction (TD) for measuring the anisotropy in Young's modulus, as well as samples for investigating the structure and texture. Samples for measurement of the elastic properties in the package were handled by a milling machine to reduce the influence on the accuracy of measurements of geometrical dimensions.

The elastic modulus was measured by dynamic method via frequency of forced flexural vibrations of a flat sample [10]. The measurement error did not exceed 1\%.

Before the study of the texture, the samples were chemically polished to the depth of $0.1 \mathrm{~mm}$ to remove the distorted surface layer. The crystallographic texture was investigated on two surfaces of the samples after the above indicated number of cycles by constructing inverse pole figures (IPFs) for the normal direction (ND) and rolling direction (RD) as well as by means of incomplete direct pole figures $\{0002\}$ $\left(0^{\circ} \leq \alpha \leq 70^{\circ}\right)$ of rolling plane using a DRON-3M diffractometer in filtered Mo K $\alpha$ radiation. A sample without texture measurements was prepared from fine recrystallized sawdust of the alloy investigated. To plot IPFs that correspond to the RD (IPF RD), composite samples were prepared. When constructing IPFs, the normalization according to Morris was used [11].

Metallographic structure was investigated in the rolling plane by means of metallographic microscope MIM-7 using the camera Veb-E-TREK DEM 200 to output the image structure on the computer monitor.

\section{Results and Discussions}

The IPFs of the samples of the Mg-5\% Li (mass) magnesium alloy investigated are shown in Figure 1. The corresponding direct pole figures are represented in Figure 2. Microstructures of the alloy are shown in Figure 3.

In the ND IPF (Figure 1(a)), the absolute maximum of the pole density (4.50) coincides with the pole $\langle 21 \overline{3} 2\rangle$ with the scattering up to pole $\langle 30 \overline{3} 2\rangle$. In the pole $\langle 0002\rangle$ a relatively high pole density of 3.00 is observed. On the corresponding direct PF (Figure 2(a)) it can be seen that the basal planes are aligned with the sheet surface, but there are splits in the texture peaks where the basal poles are rotated approximately $15^{\circ}$ towards the TD (recall that this TD coincides with the initial RD). The difference in the numerical value of the pole density on IPF and direct PF is due to their different normalization.

Thus, the texture of the initial sheet of a magnesiumlithium alloy may be described as a complicated texture of the deflected basal type with deviation angles of basal plane toward TD approximately 15 and $70^{\circ}$. In the IPF $\mathrm{RD}$, the region of the heightened pole density occupies an area bounded by the poles of $\langle 30 \overline{3} 2\rangle,\langle 11 \overline{2} 0\rangle$, and $\langle 10 \overline{1} 0\rangle$ with an absolute maximum at the pole $\langle 21 \overline{3} 1\rangle$. Thus, the rolling direction coincides mainly with the crystallographic direction $\langle 11 \overline{2} 0\rangle$ with the scattering up to $\langle 10 \overline{1} 0\rangle$. The abovedescribed texture of the initial sheet is different from the basal central type texture of pure magnesium.

We have previously observed a similar rotation of basal poles in TD direction in the study of the texture of magnesium alloy with zinc, zirconium, and rare earth metals (REM) [9]. This was to the influence of additives of REMs to the magnesium alloy, which promote activation of nonbasal deformation mechanisms, particularly of prismatic and pyramidal slip of dislocations [9].

It is known that the alloying magnesium by lithium promotes the scattering of the basal planes in the TD [12]. Alloying of magnesium by lithium eases the glide of $\langle a\rangle$ dislocations on prismatic planes because lithium reduces the hcp c/a ratio [13]. Quimby et al. [14] also reported that the critical resolved shear stress (CRSS) for basal slip in alpha solid solution (12.5 at. \% $\mathrm{Li}$ in $\mathrm{Mg}$ ) is 10 times higher than that for pure magnesium. Even when there is evidence of $\langle c+$ a) dislocation glide during deformation of $\mathrm{Mg}$ - $\mathrm{Li}$ alloys the significant role played by prismatic slip during deformation has been acknowledged [15]. Thus, the texture of the initial sheet of the alloy is caused by the activation of nonbasal mechanisms of sliding.

Twinning processes can also play some roles in the formation of the observed texture. In pure magnesium, the twinning at room temperature usually occurs on planes $\{10 \overline{1} 2\}$ although in the early work [16] needle like twins $\{30 \overline{3} 4\}$ were also observed. In [17], after the hot rolling of pure-magnesium samples made from an ingot, tension-induced $\{10 \overline{1} 2\}\langle 10 \overline{1} 1\rangle$ twins and compression-related twins $\{10 \overline{1} 1\}$ $\langle 10 \overline{1} 2\rangle$ have been revealed. The alloying and deformation performed at elevated temperatures can change the mechanisms of deformation and twinning in the alloys of magnesium [18]. For example, in [17] the formation of double-twinning structures $\{10 \overline{1} 1\}-\{10 \overline{1} 2\}$ was revealed. In the RD IPFs of the initial sample, an absolute maximum equal to 3.79 is observed at the pole $\langle 21 \overline{3} 1\rangle$ and the enhanced pole density occupies a wide region, which includes poles $\langle 30 \overline{3} 2\rangle,\langle 20 \overline{2} 1\rangle$, $\langle 10 \overline{1} 0\rangle,\langle 21 \overline{3} 0\rangle$, and $\langle 11 \overline{2} 0\rangle$ (hatched region in Figure $1(\mathrm{~b})$ ). It is interesting to note that, according to [17], this region corresponds to the orientations of secondary twins that arise after primary twinning on the planes $\{10 \overline{1} 1\}$.

In the photographs of the microstructure (Figure 3), almost equiaxed grains are seen (which is characteristic of recrystallization), the average size of which in two mutually perpendicular directions is almost identical (approximately $21 \times 26 \mu \mathrm{m})$ both in the initial state and after deformation using different numbers of $\mathrm{AB}$ cycles. Thus, the contribution of dynamic recrystallization in the texture formation under effect of the warm rolling of initial alloy sheet cannot be ruled out.

Twins also can be seen in the appropriate photographs of the microstructure of initial sample as well as after $A B$ 


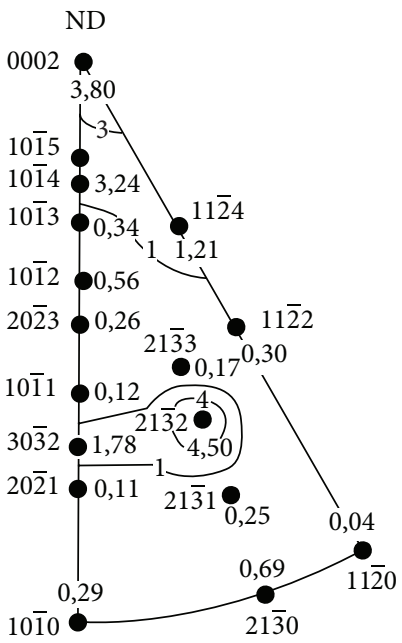

(a)

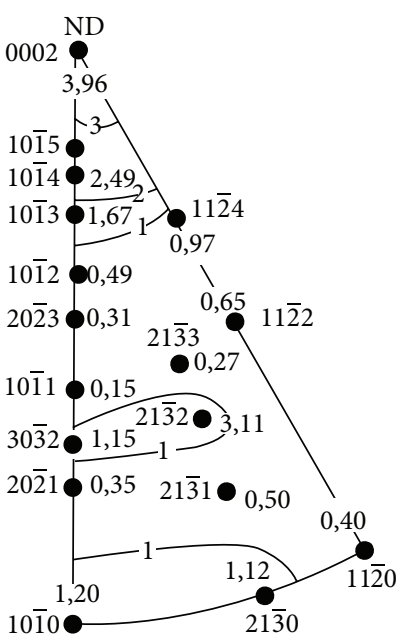

(i)

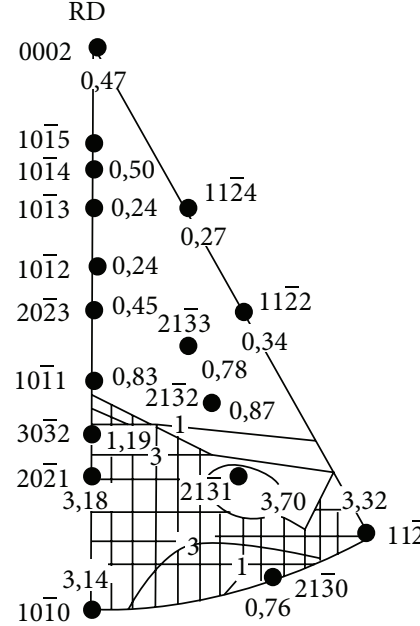

(b)

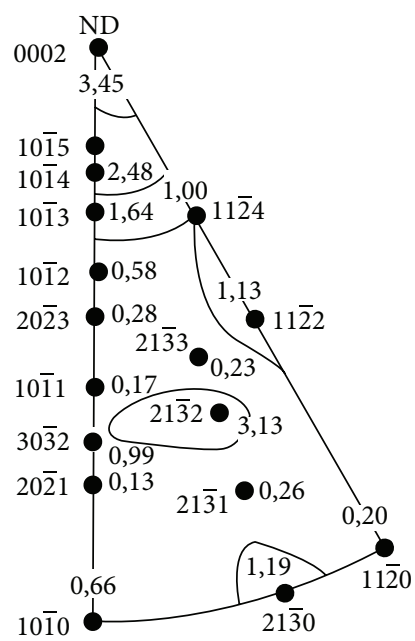

(j)

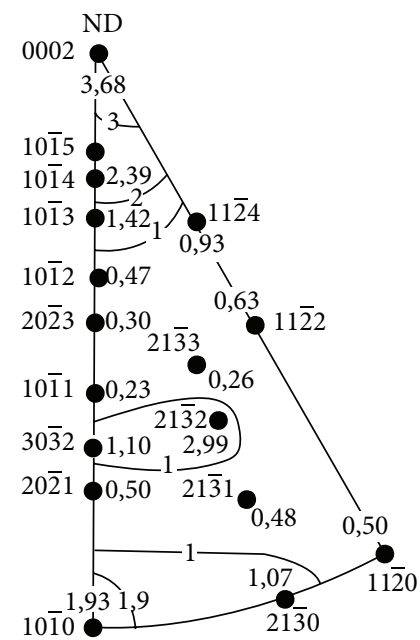

(g)
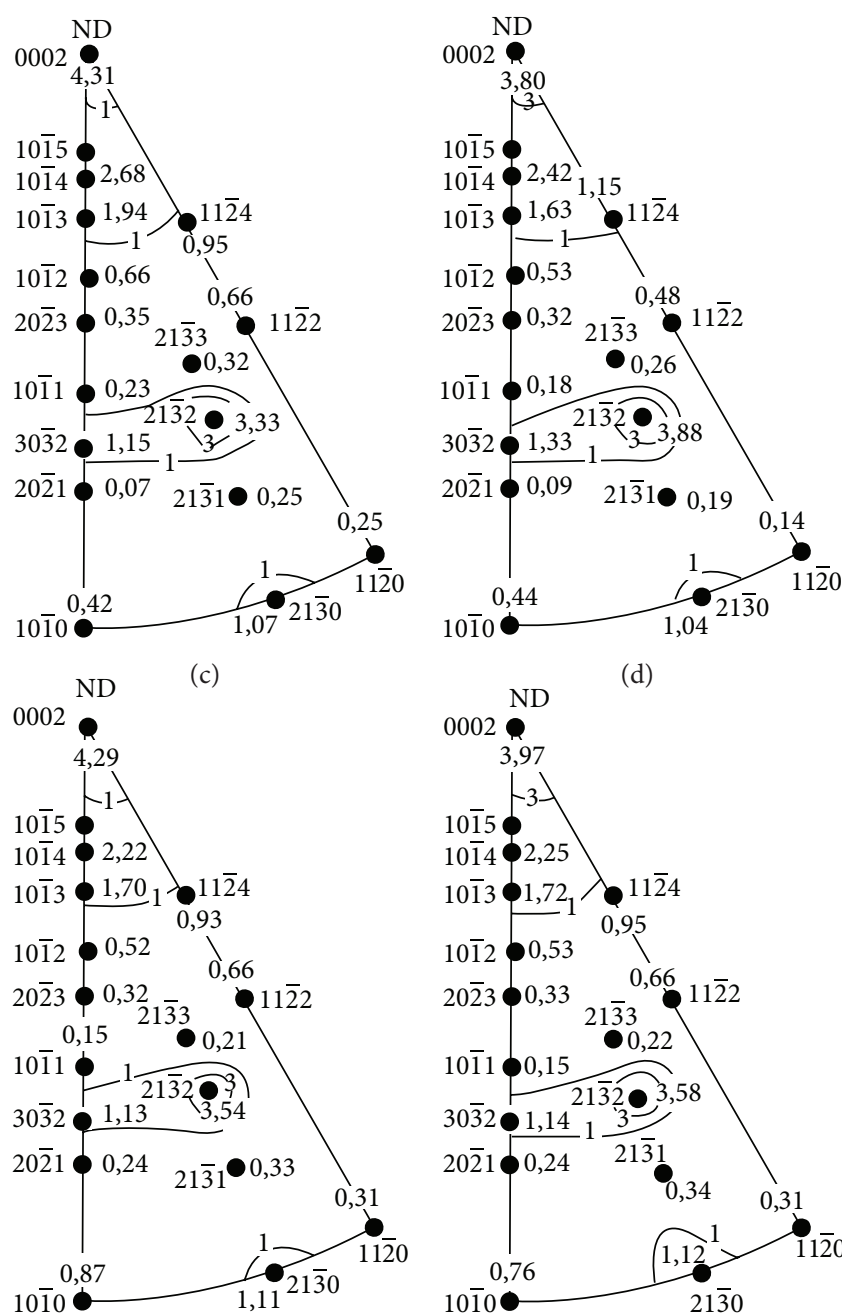

(d)

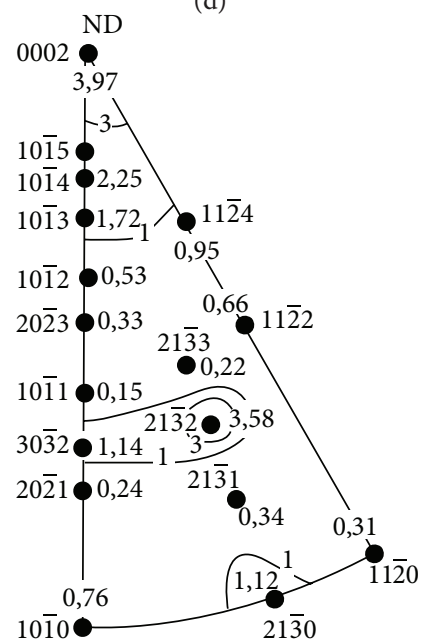

(f)

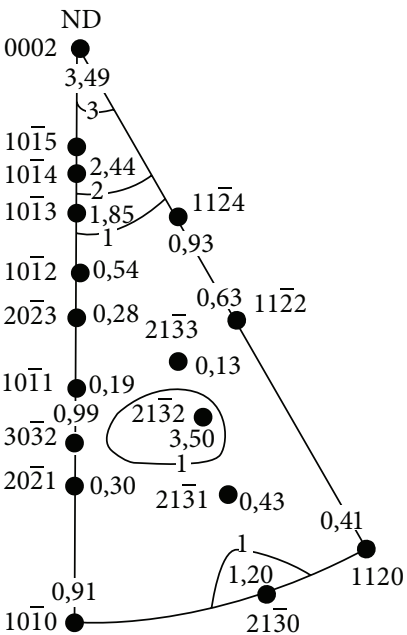

(h)

FIGURE 1: Experimental inverse pole figures of alloy Mg-5\% Li (mass): $(a, b)$ initial state; $(c-j)$ after alternating bending using different number of cycles: (c, d) 0.5 , (e, f) 1.0, (g, h) 3.0, and (i, j) 5.0 cycles. Hatched regions correspond to twin reorientations of crystals on the twinning planes $\{10 \overline{1} 0\} ;(d, f, g, i)$ correspond to the stretched side of the sheet; $(c, e, h, j)$ correspond to the compressed side of sheets of alloy. 


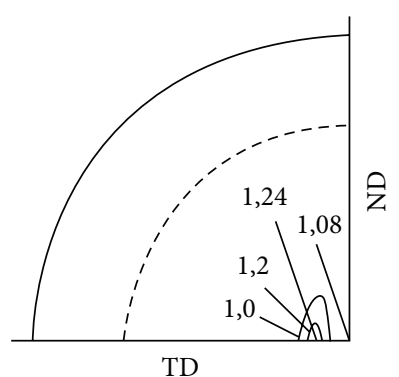

(a)

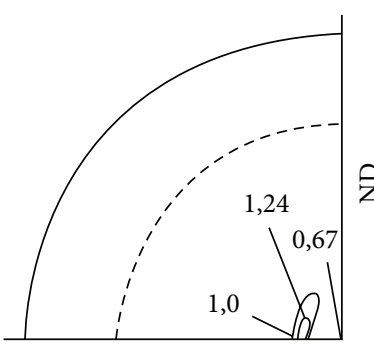

TD

(b)

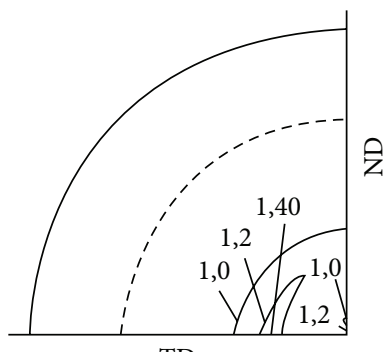

(d)

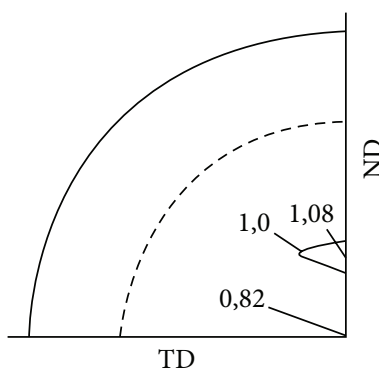

(f)

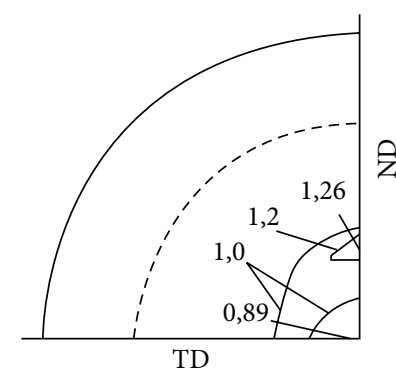

(g)

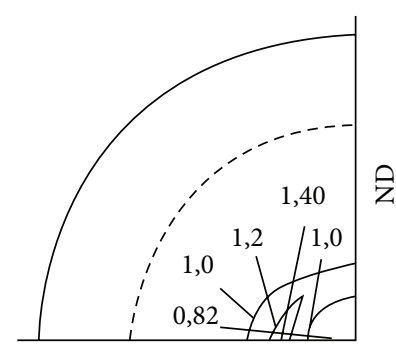

TD

(c)

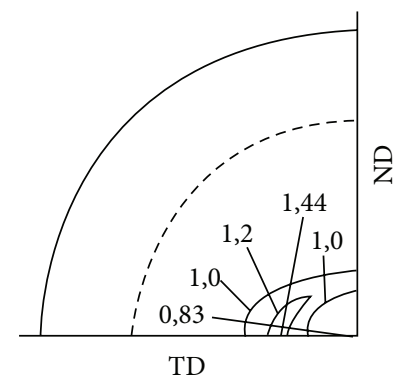

(e)

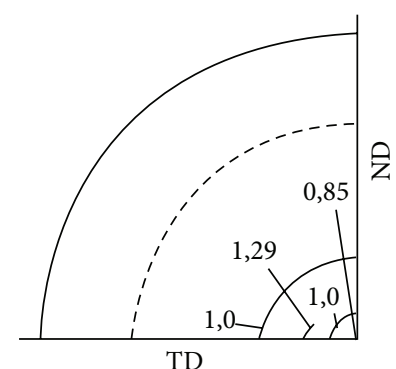

(h)

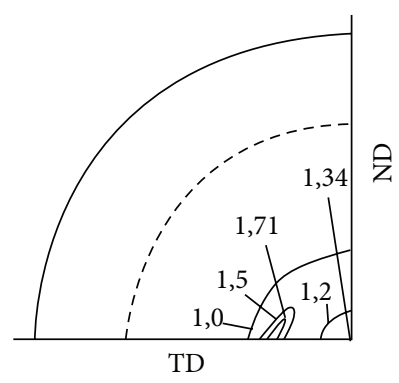

(i)

Figure 2: Experimental incomplete direct pole figures $\{0002\}$ of alloy Mg-5\% Li (mass): (a) initial state; (b-i) after alternating bending using different number of cycles: (b, c) 0.5, (d, e) 1.0, (f, g) 3.0, and (h, i) 5.0, cycles. (c, d, g, i) Correspond to the stretched side of the sheet; (b, e, f, h) correspond to the compressed side.

(Figure 3). Moreover, with the number of cycles of $A B$, the number of twins in micrographs increases. In pictures there are both broad and sharp at ends twins $(\langle 1012\rangle)$ and paired thin twins $\langle 1011\rangle$ [19].

The character of texture scattering and value of pole density on pole figures depend on the number of cycles of alternating bending (Figures 1 and 2). The IPFs (Figures 1(c), $1(\mathrm{~d}), 1(\mathrm{e})$, and $1(\mathrm{f}))$ vary a little after 0.5 and 1.0 cycles of $A B$. For example, the pole density in the pole $\langle 0002\rangle$ of IPF ND is increased slightly to 4.31 on the compressed side of sheet alloy after 0.5 cycles of $A B$ and on a stretched side of the sheet has not changed. Pole density in $\langle 21 \overline{3} 2\rangle$ decreased slightly after 0.5 cycles of $A B$.

The pole density $\langle 0002\rangle$ on IPF ND has increased to 4.29 on the compressed side of the sheet compared to the original value of 3.80 after 1.0 cycle of $\mathrm{AB}$ (Figure 1(e)). At the same time the pole density $\langle 0002\rangle$ has slightly increased to a value of 3.97 on the stretched side of the sheet (Figure 1(f)). The pole 


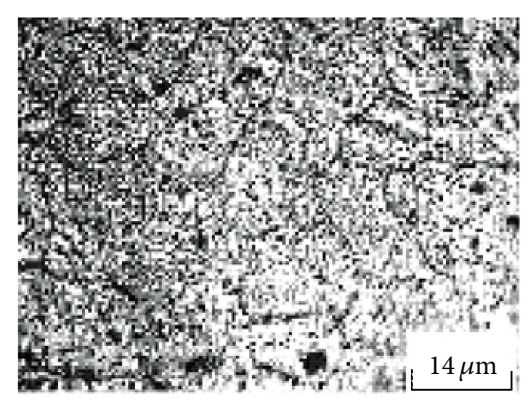

(a)

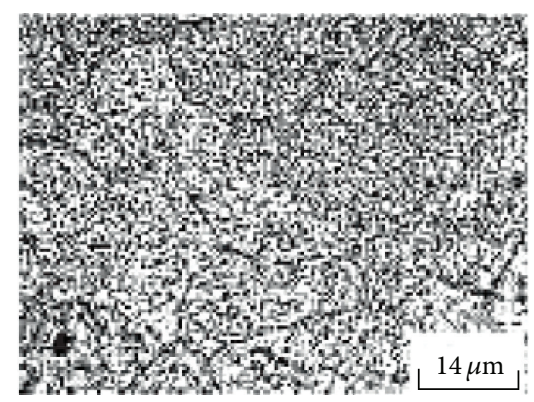

(c)

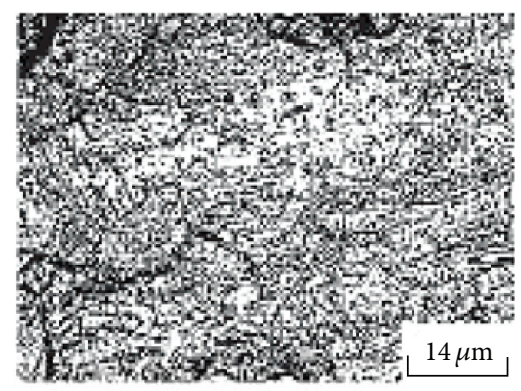

(e)

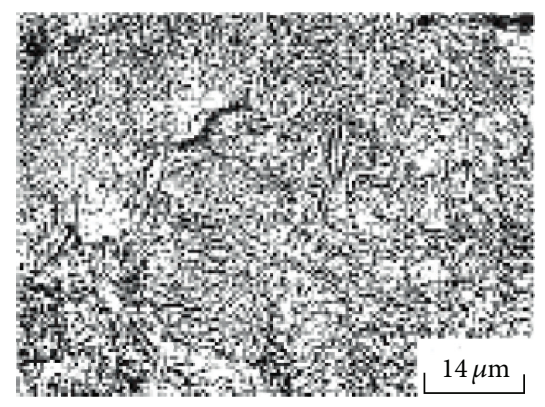

(g)

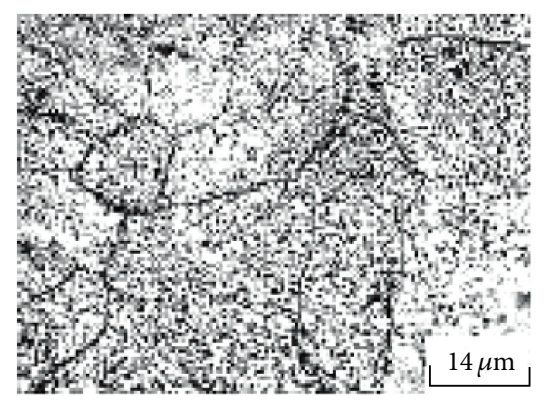

(b)

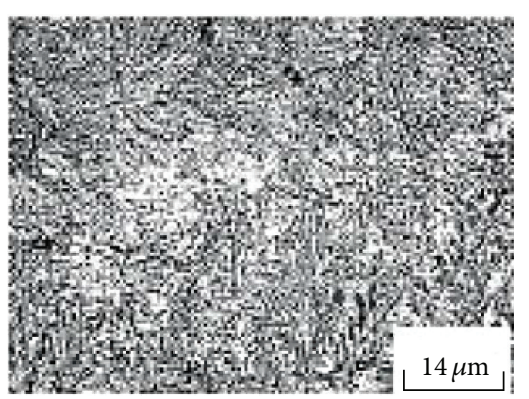

(d)

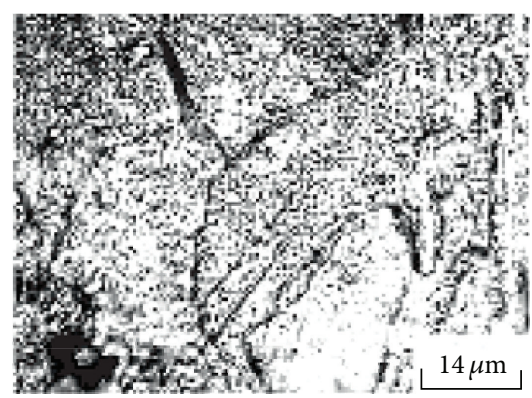

(f)

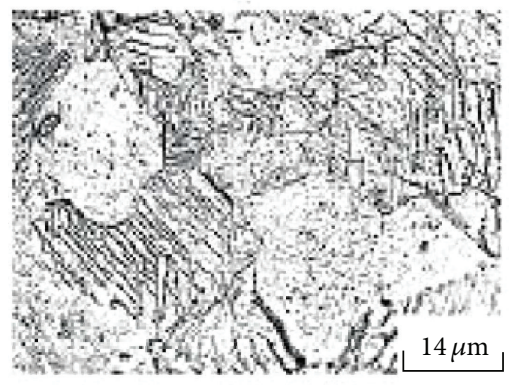

(h)

Figure 3: Microstructures of MgLi5 alloy after alternating bending using different numbers of cycles: (a, b) 0.5, (c, d) 1.0, (e, f) 3.0, and (f, h) 5 cycles; (b, c, e, g) correspond to the stretched side of the sheet; $(\mathrm{a}, \mathrm{d}, \mathrm{f}, \mathrm{h})$ correspond to the compressed side.

density $\langle 21 \overline{3} 2\rangle$ has decreased slightly to values 3.54 and 3.58 after 1.0 cycle of $A B$ on compressed and stretched side sheet, respectively (Figures $1(\mathrm{e})$ and $1(\mathrm{f})$ ).

More significant texture changes are observed after 3 and 5 cycles of $A B$. The pole density $\langle 10 \overline{1} 0\rangle$ on stretched sides of sheets reached 1.93 and 1.20 after 3 and 5 cycles of $\mathrm{AB}$, respectively. The formation of such orientations can be caused by the basal and pyramidal slip under stretching
[19]. Values of the pole density $\langle 21 \overline{3} 2\rangle$ have decreased on the stretched side (up to 2.99 and 3.11) as well as on the compressed sides of the sheets (up to 3.50 and 3.13) (Figures $1(\mathrm{~g}), 1(\mathrm{~h}), 1(\mathrm{i})$, and $1(\mathrm{j}))$. The local maximum of 1.13 is observed at the pole $\langle 1132\rangle$ on the IPF ND of compressed sheet side after 5 cycles of $\mathrm{AB}$ (Figure 1(j)). This maximum corresponds to a twin orientation with the twinning plane of $\{11 \overline{2} 2\}$ [20]. 


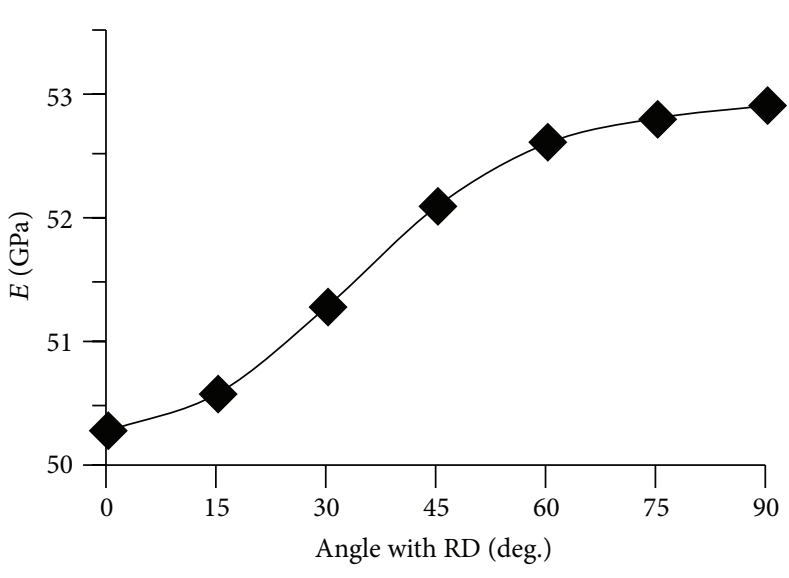

(a)

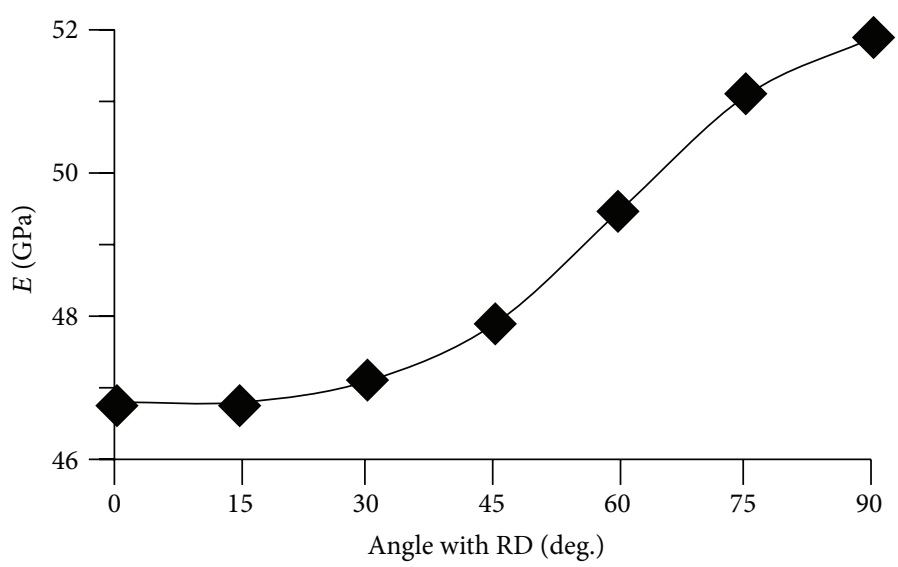

(c)

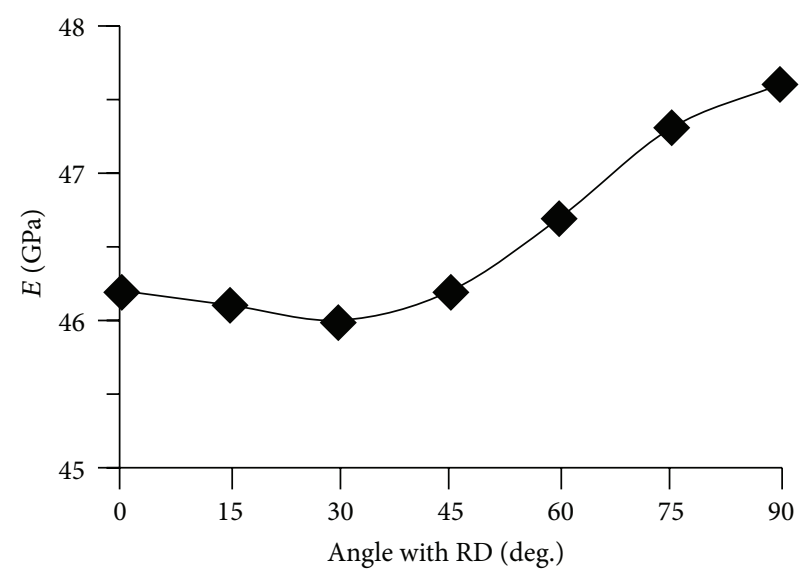

(b)

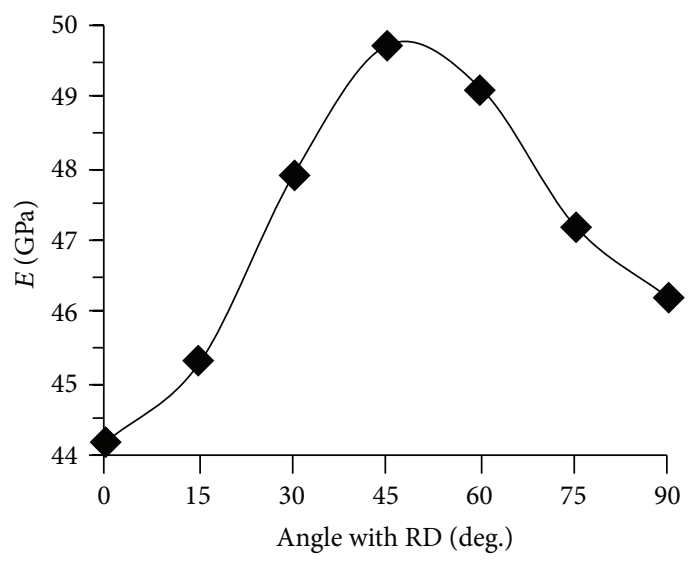

(d)

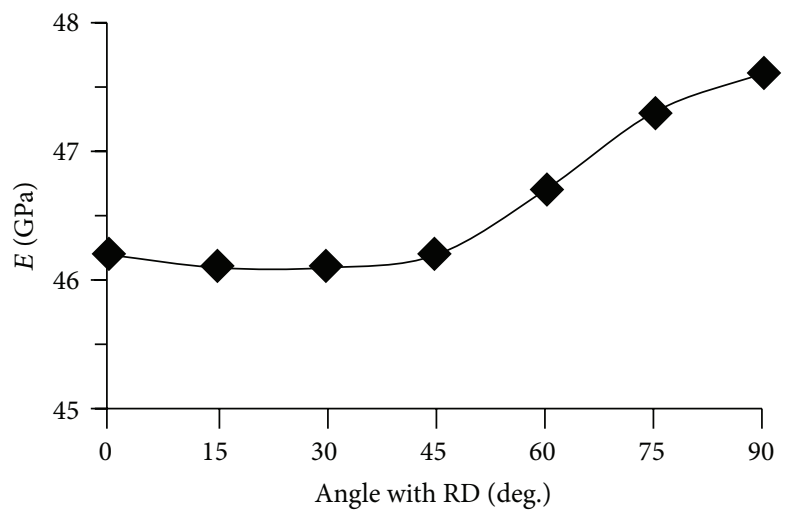

(e)

Figure 4: Elastic properties of alloy sheet (a), (b), (d), (c), and (e) after 0, 0.5, 1.0, 3.0, and 5.0 cycles of AB, respectively.

The pole density $\langle 21 \overline{3} 0\rangle$ has become more than 1 (Figure 1) on all IPFs RD after $A B$. This indicates that scattering of basal plane reached $90^{\circ}$ in the TD.

Direct PFs (Figure 2) show that the texture scattering and its average sharpness have increased after 0.5 cycles of the $A B$. Average sharpness of texture and its scattering have increased also after 1 cycle of AB. Texture has changed after 3 cycles of $A B$. Now the pole density maximum is observed in $R D$, but not in the TD. The location of maximums after 5 cycles of
$\mathrm{AB}$ again becomes similar to what was after 0.5 and 1 cycles of $\mathrm{AB}$. The texture scattering has increased, as well as the average value of the basal pole density on the centre of direct PF $\{0002\}$ has increased.

The above-described texture changes are reflected in the behavior of the curves of the anisotropy of the elastic properties (Figure 4). The maximum value of Young's modulus is observed in the TD in initial sheet as well as after $0.5,1$, and 5 cycles of AB (Figures 4(a), 4(b), 4(c), and 4(e)). But after 3 
cycles of $\mathrm{AB}$ a maximum of Young's modulus is observed in $\mathrm{RD}+45^{\circ}$ (Figure $4(\mathrm{~d})$ ). Young's modulus has the minimum value in the $\mathrm{RD}+30^{\circ}$ after 0.5 and 5 cycles of $\mathrm{AB}$ (Figures 4(b) and 4(e)). The minimal value in the RD shows Young's modulus in the initial sheet and after 1 and 3 cycles of $A B$ (Figures 4(a), 4(c), and 4(d)).

The anisotropy degree of Young's modulus can be represented quantitatively by the anisotropy coefficient:

$$
\eta=\frac{E_{\max }-E_{\min }}{E_{\min }} \times 100 \%,
$$

where $E$ is Young's modulus. The initial material anisotropy coefficient $\eta$ is $4.5 \%$. After $0.5,1,3$, and 5 cycles of $\mathrm{AB} \eta$ is $3.4 \%, 10.7 \%, 12.5$, and $3.3 \%$, respectively.

The minimum anisotropy of the elastic properties after 5 cycles of $\mathrm{AB}$ is explained by increasing of texture scattering and density of basal poles in the centre of PF $\{0002\}$ (Figures 2(h) and 2(i)).

\section{Conclusion}

(1) Of the initial sheet MgLi5 (mass) alloy received by warm cross-rolling is different from the basal central type texture of pure magnesium. The texture of the initial sheet of MgLi5 (mass) alloy may be described as a complicated texture of the deflected basal type with deviation angles of basal plane toward transverse direction of approximately 15 and $70^{\circ}$. The rolling direction coincides mainly with the crystallographic direction $\langle 11 \overline{2} 0\rangle$ with the scattering up to $\langle 10 \overline{1} 0\rangle$. Such texture may be caused by the activation of nonbasal mechanisms of sliding as well as twinning due to the alloying by lithium. The contribution of dynamic recrystallization in the texture formation under effect of the warm rolling of initial alloy sheet cannot be ruled out.

(2) The character of texture scattering and value of pole density on pole figures depend on the number cycles of alternating bending. More significant texture changes are observed after 3 and 5 cycles of alternating bending. The texture scattering is increased, and the average value of the basal pole density in the centre of direct PF $\{0002\}$ increased as well with the increasing of number cycles of alternating bending. The number of twins on respective images of the microstructure is also increased.

(3) The texture changes are reflected in the anisotropy of the elastic properties. Young's modulus has maximum in the transverse direction in the initial sheet, as well as after $0.5,1$, and 5 cycles of alternating bending. After 3 cycles of alternating bending a maximum of Young's modulus is observed in $\mathrm{RD}+45^{\circ}$. The minimal Young's modulus takes place in the rolling direction in the initial sheet, as well as after 1 and 3 cycles of alternating bending. Young's modulus has a minimum in the RD $+30^{\circ}$ after 0.5 and 5 cycles of alternating bending.

\section{Conflict of Interests}

The authors declare that there is no conflict of interests regarding the publication of this paper.

\section{References}

[1] Z. Yang, J. P. Li, J. X. Zhang, G. W. Lorimer, and J. Robson, "Review on research and development of magnesium alloys," Acta Metallurgica Sinica, vol. 21, no. 5, pp. 313-328, 2008.

[2] H. Haferkamp, R. Boehm, U. Holzkamp, C. Jaschik, V. Kaese, and M. Niemeyer, "Alloy development, processing and applications in magnesium lithium alloys," Materials Transactions, vol. 42, no. 7, pp. 1160-1166, 2001.

[3] Technology of sraightening in ARKU rollers, http://www.tkzentrum.ru/equipment/arku/item17/.

[4] Y. V. Zilberg, F. Bach, D. Bormann, M. Rodman, M. Sharper, and M. Hepke, "Effect of alternating bending on the structure and properties of strips from AZ31 magnesium alloy," Metal Science and Heat Treatment, vol. 51, no. 3-4, pp. 170-175, 2009.

[5] A. A. Bryukhanov, P. P. Stoyanov, Yu. V. Zilberg, and D. Rodman, "Anisotropy of mechanical properties of magnesium alloy AZ31 sheets as a result of sign-variable bending deformation," Metallurgical and Mining Industry, vol. 2, no. 3, pp. 215-219, 2010.

[6] A. A. Bryukhanov, M. Rodman, A. F. Tarasov, P. P. Stoyanov, M. Shaper, and D. Bormann, "Mechanism of the plastic deformation of the AZ31 alloy upon low-cycle reverse bending," Physics of Metals and Metallography, vol. 111, no. 6, pp. 623-629, 2011.

[7] T. Uota, T. Suzu, S. Fukumoto, and A. Yamamoto, "EBSD observation for reversible behavior of deformation twins in AZ31B magnesium alloy," Materials Transactions, vol. 50, no. 8, pp. 2118-2120, 2009.

[8] V. V. Usov, P. A. Bryukhanov, M. Rodman et al., "Influence of reversed bending on texture, structure and mechanical properties of $\alpha$-titanium sheets," Deformation and Fracture of Materials, no. 9, pp. 32-37, 2012.

[9] N. M. Shkatulyak, V. V. Usov, N. A. Volchok et al., "Effect of reverse bending on texture, structure, and mechanical properties of sheets of magnesium alloys with zinc and zirconium," The Physics of Metals and Metallography, vol. 115, no. 6, pp. 609-616, 2014.

[10] ATCP, "Elastic moduli: overview and characterization methods," Technical Review ITC-ME/ATCP, 2010, http://www.atcpndt.com/images/products/sonelastic/articles/RT03-ATCP.pdf.

[11] P. R. Morris, "Reducing the effects of nonuniform pole distribution in inverse pole figure studies," Journal of Applied Physics, vol. 30, no. 4, pp. 595-596, 1959.

[12] L. W. F. Mackenzie and M. Pekguleryuz, "The influences of alloying additions and processing parameters on the rolling microstructures and textures of magnesium alloys," Materials Science and Engineering A, vol. 480, no. 1-2, pp. 189-197, 2008.

[13] F. E. Hauser, P. R. Landon, and J. E. Dorn, "Deformation and fracture of alpha solid. Solutions of lithium in magnesium," Transactions of American Society for Metals, vol. 50, pp. 856883, 1958.

[14] R. M. Quimby, J. D. Mote, and J. E. Dorn, "Yield point phenomena in magnesium-lithium single crystals," Transactions of American Society for Metals, vol. 55, pp. 149-157, 1962.

[15] S. R. Agnew, P. Mehrotra, T. M. Lillo, G. M. Stoica, and P. K. Liaw, "Texture evolution of five wrought magnesium alloys 
during route a equal channel angular extrusion: experiments and simulations," Acta Materialia, vol. 53, no. 11, pp. 3135-3146, 2005.

[16] S. L. Couling and C. S. Roberts, "New twinning systems in magnesium," Acta Crystallographica, vol. 9, no. 11, pp. 972-973, 1956.

[17] M. R. Barnett, Z. Keshavarz, A. G. Beer, and X. Ma, "NonSchmid behaviour during secondary twinning in a polycrystalline magnesium alloy," Acta Materialia, vol. 56, no. 1, pp. 5-15, 2008.

[18] J. Koike and D. Ando, "Strain accommodation twins and fracture initiation twins in magnesium alloys," http://www.magnet .ubc.ca/news/images/MagNET\%20Workshop\%20Abstracts.pdf.

[19] M. R. Barnett, "Twinning and the ductility of magnesium alloys. Part II. "Contraction" twins," Materials Science and Engineering A, vol. 464, no. 1-2, pp. 8-16, 2007.

[20] Ya. D. Vishnyakov, A. A. Babareko, S. A. Vladimirov, and I. V. Egiz, Theory of Texture Formation in Metals and Alloys, Nauka, Moscow, Russia, 1979 (Russian). 

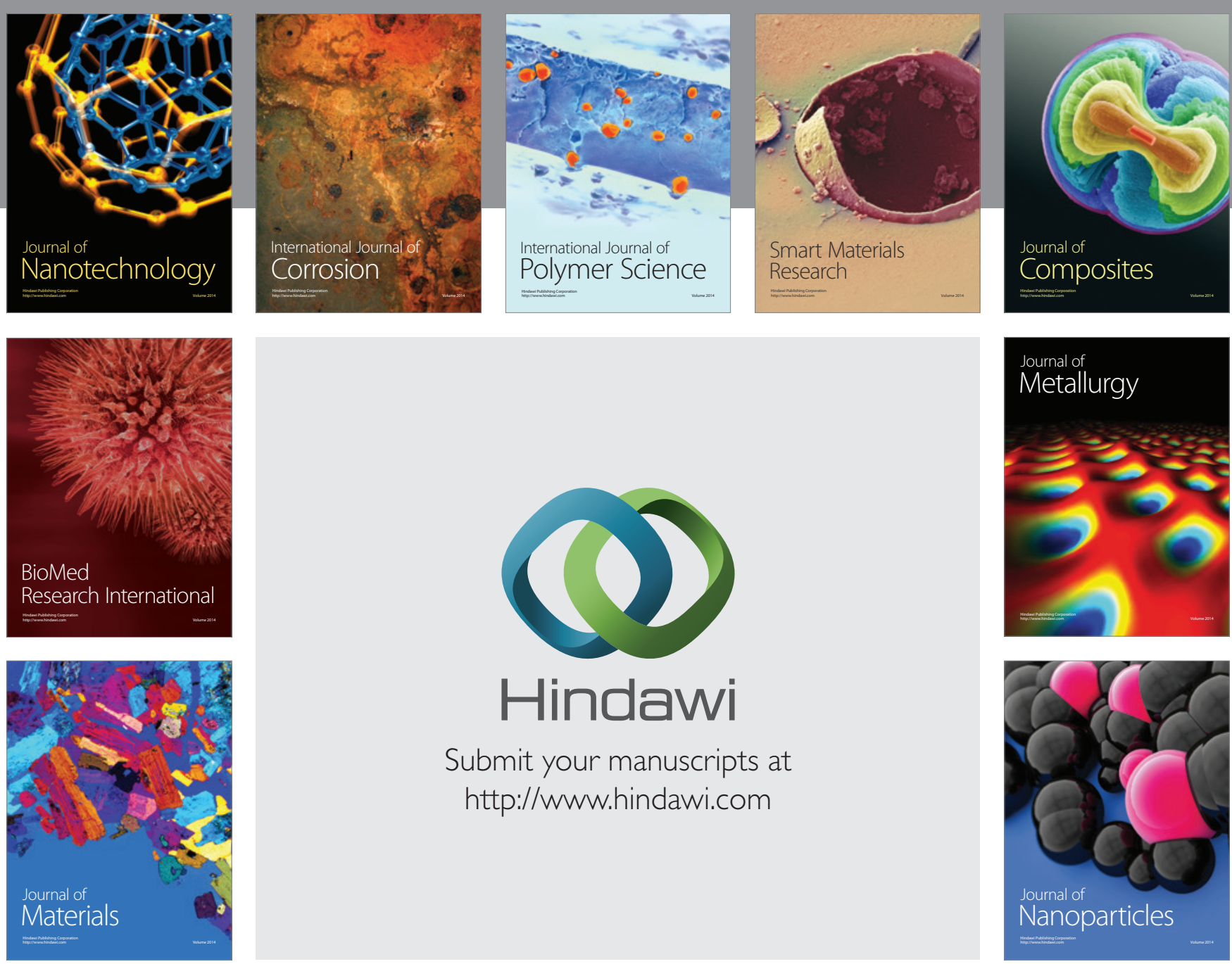

Submit your manuscripts at http://www.hindawi.com
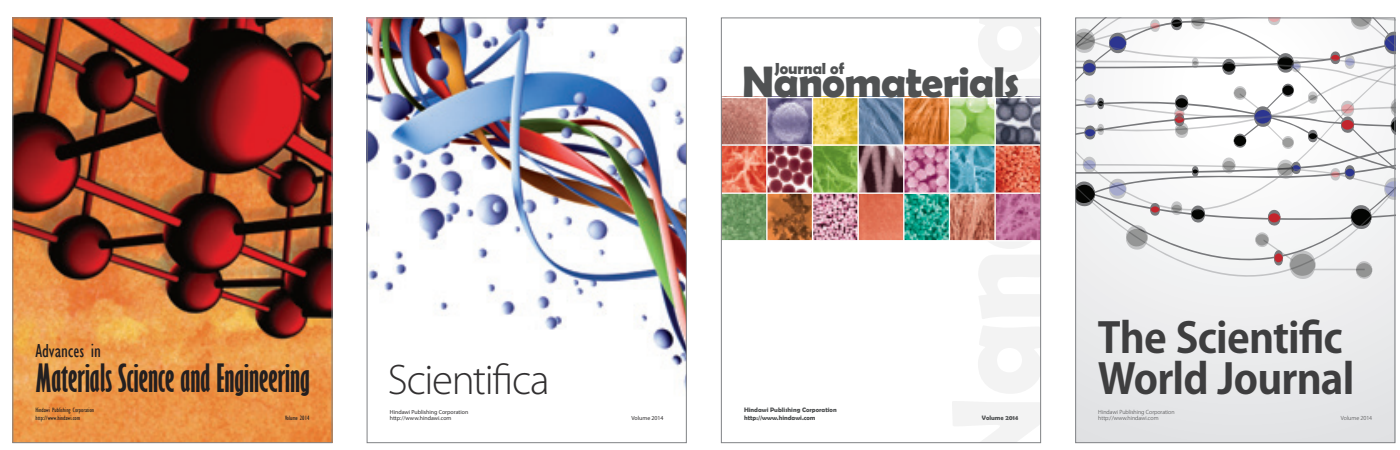

\section{The Scientific World Journal}
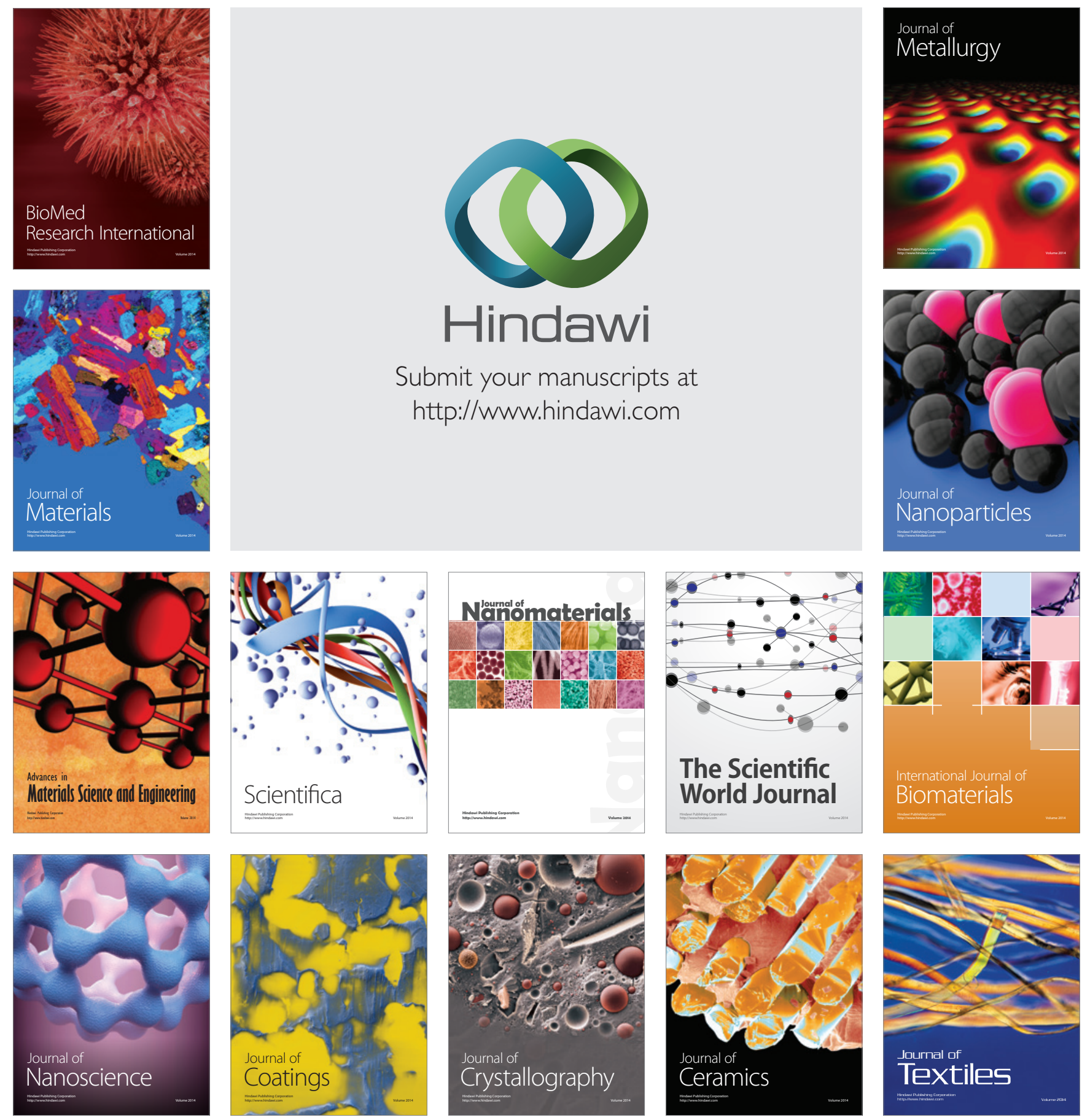